\title{
ASPECTOS GERAIS SOBRE OS PRINCÍPIOS GERAIS DA CONTABILIDADE E DA ADMINISTRAÇÃO PÚBLICA E O PAPEL PREPONDERANTE DA CONTABILIDADE PÚBLICA NA PROBIDADE ADMINISTRATIVA
}

Luis Gustavo Esse

Discente do curso de Ciências Contábeis do Centro Universitário Internacional (UNINTER). E-mail: Isgustavo92@ig.com.br.

RESUMO: Este artigo visa estabelecer um paradoxo entre os princípios da profissão contábil, estabelecidos pela Resolução do CFC n‥ 750/1993, para com os princípios da Administração Pública, trazidos pela Constituição Federal, identificando as relações entre ambos os instrumentos normativos na aplicabilidade da contabilidade no setor público, ressaltando a importância do bom uso da contabilidade para a boa gestão da Administração Pública.

Palavras-Chaves: Direito Administrativo. Contabilidade Pública. Probidade Administrativa. Gestão Pública.

\section{INTRODUÇÃO}

Com o advento da constituição de 1988, a discussão acerca da probidade administrativa intensificou-se no cenário nacional, tendo o legislador constituinte, a preocupação de estabelecer princípios para a administração pública, o que constituiu em um significativo avanço em relação à condição anterior do Direito Administrativo, que se encontrava até então, sem nenhum parâmetro constitucional, situação hoje revertida, com a edição do Art. 37, caput, da Constituição Federal, que estabeleceu os parâmetros maiores deste ramo do direito.

Por outro lado, temos a contabilidade, que também têm sofrido fortes transformações nas últimas décadas, principalmente o ramo da contabilidade pública, que se não bastasse às transformações sofridas pela contabilidade, como um todo, este ramo da contabilidade também sofreu transformações significativas, graças às mudanças ocorridas no Direito Administrativo, na década de 1990.

Após a promulgação da vigente constituição, importantes normas foram editadas para a Contabilidade Pública, dentre as quais podemos citar a Resolução do Conselho Federal de Contabilidade (CFC) de no. 750/1993, a Lei de Improbidade Administrativa (Lei no. 8.429/1992) e por fim, a Lei de Responsabilidade Fiscal (Lei Complementar no. 101/2000). Todas estas normas são de suma relevância para a o ramo da contabilidade pública e do direito administrativo, que passaram a desenvolver uma relação de interdependência, com a "nova Administração Pública", introduzida pela vigente constituição. 
Quanto à aplicabilidade destas novas normas e práticas contábeis para o setor público, é importante fazer um paradoxo entre as novas exigências previstas para o setor público na prestação de contas e contratação de serviços, bem como as novas atribuições conquistadas pelos Tribunais de Contas, neste mesmo período, para que se torne suficientemente clara a aplicabilidade destas novas normas na contabilidade pública e seus principais reflexos no cotidiano da Administração Pública.

\section{INTERPRETAÇÃO DOS PRINCÍPIOS DA RESOLUÇÃO DO CFC No. 750/1993 SOB A ÓTICA DOS PRINCÍPIOS CONSTITUCIONAIS DA ADMINISTRAÇÃO PÚBLICA}

Considerando a importância dos princípios constitucionais da administração pública, como parâmetro de orientação para as práticas da contabilidade pública, de forma conjunta com as disposições da resolução do CFC no. 750/1993, devemos estabelecer um comparativo entre ambos os diplomas legais, com o fim de compreender a aplicabilidade dos princípios trazidos por esta última norma na Administração Pública.

Primeiramente, devemo-nos recordar da conceituação básica de cada um destes princípios, começando primeiramente com os princípios contábeis, definidos por Carlos Alberto de Ávila ${ }^{1}$ como responsáveis para o balizamento das ações dos profissionais da área contábil.

O Art. 3ำ, da Resolução no. 750/1993 sumariza estes princípios definidos ao longo do texto da resolução, cujos quais citaremos adiante.

\subsection{Princípios da Prática Contábil}

Conforme mencionado, estes princípios constantes a seguir, orientam o profissional contábil, para a boa prática contábil. Recorreremos à explicação de Júlio César Zanluca ${ }^{2}$, que nos traz de forma bastante concisa e explicativa, a explicação de cada um destes princípios trazidos pelo texto Resolução no. 750/1993, conforme a seguir:

\section{O PRINCÍPIO DA ENTIDADE}

O Princípio da ENTIDADE reconhece o Patrimônio como objeto da Contabilidade e afirma a autonomia patrimonial, a necessidade da diferenciação de um Patrimônio particular no universo dos patrimônios existentes, independentemente de pertencer a uma pessoa, um conjunto de pessoas, uma sociedade ou instituição de qualquer natureza ou finalidade, com ou sem fins lucrativos.

\footnotetext{
${ }^{1}$ AVILA, Carlos Roberto. Gestão Contábil Para Contadores e Não Contadores. 2ạ. Edição. Revista, Atualizada e Ampliada. - Curitiba: Ibpex, 2011. Página: 26.

2 ZANLUCA, Júlio Os Cesar. Os da http://www.portaldecontabilidade.com.br/tematicas/principiosfundamentais.htm. Acessado em: 5 de Junho de 2013. 
Por consequência, nesta acepção, o Patrimônio não se confunde com aqueles dos seus sócios ou proprietários, no caso de sociedade ou instituição.

\section{O PRINCÍPIO DA CONTINUIDADE}

O Princípio da Continuidade pressupõe que a Entidade continuará em operação no futuro e, portanto, a mensuração e a apresentação dos componentes do patrimônio levam em conta esta circunstância.

\section{O PRINCÍPIO DA OPORTUNIDADE}

O Princípio da Oportunidade refere-se ao processo de mensuração e apresentação dos componentes patrimoniais para produzir informações íntegras e tempestivas.

\section{O PRINCÍPIO DO REGISTRO PELO VALOR ORIGINAL}

O Princípio do Registro pelo Valor Original determina que os componentes do patrimônio devam ser inicialmente registrados pelos valores originais das transações, expressos em moeda nacional.

Uma vez integrado ao patrimônio, os componentes patrimoniais, ativos e passivos, podem sofrer variações decorrentes dos seguintes fatores:

a) Custo corrente. Os ativos são reconhecidos pelos valores em caixa ou equivalentes de caixa, os quais teriam de ser pagos se esses ativos ou ativos equivalentes fossem adquiridos na data ou no período das demonstrações contábeis. Os passivos são reconhecidos pelos valores em caixa ou equivalentes de caixa, não descontados, que seriam necessários para liquidar a obrigação na data ou no período das demonstrações contábeis;

b) Valor realizável. Os ativos são mantidos pelos valores em caixa ou equivalentes de caixa, os quais poderiam ser obtidos pela venda em uma forma ordenada. Os passivos são mantidos pelos valores em caixa e equivalentes de caixa, não descontados, que se espera seriam pagos para liquidar as correspondentes obrigações no curso normal das operações da Entidade;

c) Valor presente. Os ativos são mantidos pelo valor presente, descontado do fluxo futuro de entrada líquida de caixa que se espera seja gerado pelo item no curso normal das operações da Entidade. Os passivos são mantidos pelo valor presente, descontado do fluxo futuro de saída líquida de caixa que se espera seja necessário para liquidar o passivo no curso normal das operações

da

Entidade;

d) Valor justo. É o valor pelo qual um ativo pode ser trocado, ou um passivo liquidado, entre partes conhecedoras, dispostas a isso, em uma transação sem favorecimentos;

e) Atualização monetária. Os efeitos da alteração do poder aquisitivo da 
moeda nacional devem ser reconhecidos nos registros contábeis mediante o ajustamento da expressão formal dos valores dos componentes patrimoniais.

\section{O PRINCÍPIO DA COMPETÊNCIA}

O Princípio da Competência determina que os efeitos das transações e outros eventos sejam reconhecidos nos períodos a que se referem, independentemente do recebimento ou pagamento. Parágrafo único. 0 Princípio da Competência pressupõe a simultaneidade da confrontação de receitas e de despesas correlatas.

\section{O PRINCÍPIO DA PRUDÊNCIA}

O Princípio da PRUDÊNCIA determina a adoção do menor valor para os componentes do ATIVO e do maior para os do PASSIVO, sempre que se apresentem alternativas igualmente válidas para a quantificação das mutações patrimoniais que alterem o patrimônio líquido.

Os princípios acima mencionados, com a definição explicativa do Júlio César Zanuca conforme mencionado, são de observância obrigatória pelo profissional contábil, muito embora seja de conhecimento geral, que em muitos casos, estes princípios são infligidos, principalmente o Princípio da Entidade, na contabilidade das micro e pequenas empresas, aonde, muitas vezes, os sócios "injetam" parte do patrimônio pessoal na empresa, sem realizar a devida contabilização do fato, de forma correta, acarretando num falso quadro da situação da empresa, impossibilitando a verificação da situação real de lucratividade existente na mesma.

Note que, uma simples atitude de inserir capital externo na empresa, sem a devida contabilização correta, causa um efeito drástico para a principal função da contabilidade, que é o estudo da composição e mutação patrimonial das entidades, portanto, o desrespeito a qualquer um destes princípios, simplesmente desvirtuam a prática contábil de seu ideal.

\subsection{Relação dos Princípios da Profissão Contábil com os Princípios Constitucionais da Administração Pública}

Em primeiro momento, é difícil enxergar qualquer relação entre os princípios da profissão contábil com os princípios da administração pública, por este motivo, não se trata de um comparativo normativo, mas sim de uma interpretação diferenciada dos princípios da profissão contábil a luz dos princípios constitucionais da administração pública, em outras palavras, esta síntese se constitui nos princípios do profissional de contábil no setor público. Recordemo-nos a seguir, quais são estes princípios constitucionais da Administração Pública, antes de estabelecer o paradoxo entre as normas: 
Art. 37. A administração pública direta e indireta de qualquer dos Poderes da União, dos Estados, do Distrito Federal e dos Municípios obedecerá aos princípios de legalidade, impessoalidade, moralidade, publicidade e eficiência ${ }^{3}$.

Evidentemente que o confronto entre os princípios da Administração Pública e os da Profissão Contábil nem sempre permitem uma síntese interpretativa, mas apenas um complemento ao outro princípio existente. Sendo assim, dentre os princípios da Administração Pública, poderíamos citar apenas três destes princípios (legalidade, moralidade e eficiência), para os fins da realização desta síntese mencionada.

\subsubsection{Princípio Constitucional da Legalidade}

De acordo com Irene Patrícia Nohara ${ }^{4}$, a Administração Pública, diferentemente dos cidadãos, somente pode fazer aquilo que a lei permite, pois conforme a autora aponta em sua obra, o jurista alemão Hans Kelsen dizia que a Administração Pública tinha vinculação positiva para com este direito fundamental, isto é, diferentemente do cidadão, ela deveria seguir estritamente o que estivesse previsto em lei, enquanto os cidadãos podem fazer tudo aquilo, salvo o que for proibido em lei.

Sob o prisma dos princípios da profissão contábil, podemos dizer que a lei exerce papel preponderante para a sua prática no setor público, estabelecendo novos princípios e como a aplicação de alguns de seus princípios no setor público, podendo-se tomar como exemplo, o Princípio da Entidade, no qual a lei estabelece a criação de um novo ente ou empresa pública, que passa a se constituir de fato, em uma nova entidade, para os fins do estudo das mutações patrimoniais da contabilidade.

Por este motivo, a contabilidade no setor público é setorizada, isto é, estudada para cada setor que compõe o setor público de forma individual e independente, não existindo assim, uma só contabilidade para toda a Administração Pública, mas sim, vários estudos contábeis, para cada ente do setor público, pois, sob a ótica contábil, cada um destes constitui uma entidade, pois tiveram criações autônomas e distintas, como se fossem empresas pertencentes a um determinado grupo de empresas.

\footnotetext{
${ }^{3}$ BRASIL, República Federativa do. Constituição Federal. - Brasília: Senado, 1988.

${ }^{4}$ NOHARA, Irene Patrícia. Direito Administrativo. - 2a edição. - São Paulo: Atlas: 2012. 
Podemos invocar a influência do Princípio da Legalidade também sobre o Princípio da Entidade, quanto à aplicação de recursos de outro ente da Administração Pública, só que neste caso, há um pequeno detalhe a ser observado, que é quanto à natureza do ente público em questão, se ele possui ou não fins lucrativos.

A introdução de recursos em entes públicos vinculados a outro ente público é uma prática bastante comum no Brasil, realizada muitas vezes através de atos normativos, como leis e decretos, emanados pelo Poder Legislativo ou Executivo do ente federativo que o ente público encontra-se vinculado. Entretanto, de acordo com o princípio da entidade, o patrimônio da entidade não deveria sofrer intervenção de patrimônios externos, para que fosse possível analisar a situação econômica da entidade. Todavia, no caso da Administração Pública, este princípio deve ser relativizado, haja vista o interesse público que há naquele órgão, desta forma, conforme mencionado anteriormente, deve-se observar a natureza daquele ente público, ou seja, se ele tem ou não fins lucrativos.

Quando o ente público não possui fins lucrativos, a inserção de recursos por parte da Administração Pública superior é simplesmente lógica, haja vista que a sobrevivência daquele ente público depende daquele recurso, logo, ainda que este arrecade receitas, estas podem não ser suficientes para sua subsistência ou mesmo a realização de sua finalidade principal. Assim, como não é de interesse social, fechar aquela entidade, o único meio de mantê-la em funcionamento, é através desta transferência monetária, sem vincular o ente beneficiado, em qualquer obrigação que vise à devolução da quantia a entidade concedente.

Por outro lado, quando se trata de uma entidade que possui plena capacidade de gerar receitas com seus proventos, mas que por um determinado período, encontra-se em dificuldades financeiras e é de relevante interesse social e talvez econômico, garantir sua existência, o recurso aplicado pelo ente superior constitui-se como empréstimo, assim como na contabilidade para as pessoas de Direito Privado, estabelecendo a obrigatoriedade de devolução após determinado prazo.

Esta diferenciação é importante de ser realizada, mostrando uma supremacia da lei que conceder o recurso, sobre este princípio profissional (princípio da entidade), com base no interesse social. Todavia, devemos lembrar que estes casos são excepcionais, e que os princípios da profissão contábil devem prevalecer para a boa prática contábil.

\subsubsection{Princípio Constitucional da Moralidade}


Talvez este seja o principio que propicie maior consonância com os postos como princípios da profissão contábil, pois, não somente para a prática contábil na Administração Pública, como também para toda a pratica profissional, contábil ou não, este princípio deveria ser observado, pois ele está fortemente atrelado à ética profissional.

\section{CONCLUSÃO}

É evidente que após 1988 houveram grandes mudanças na forma em que se passou a organizar a administração pública, graças a introdução dos princípios constitucionais para o funcionamento desta, todavia, é importante destacar o liame surgido entre estes princípios e os princípios elaborados pelo CFC para todos os profissionais contábeis, ou seja, a questão da honestidade funcional parece-me que não se tornou apenas uma preocupação para a administração pública, mas para a função do contador em si, denotando tamanha a importância desta virtude para o bom exercício profissional da contabilidade.

Desta forma, a revolução que a contabilidade vem sofrendo, buscando com isto, a valorização da carreira profissional em razão do ganho de espaço e responsabilidades que tem ganho a carreira, tornou-se mais notável este fenômeno ainda, no setor público, aonde, toda uma estrutura administrativa pré-existente a 1988, passa a sofrer constantes transformações, que, junto às ciências contábeis, faz com que a profissão do contabilista atuante no setor público, esteja em constante transformação, devendo acompanhar este dinamismo para se adequar aos novos tempos de sua profissão.

Além disto, devemo-nos lembrar de que com o ganho de responsabilidade, a função do contador público tornou-se fundamental para a probidade na administração pública, como também tornou-se fundamental para o bom exercício da democracia no país, pois, até os dias atuais, as demonstrações contábeis dos entes públicos, são ainda o único mecanismo que permite que os indivíduos possam saber acerca da saúde financeira dos entes públicos, cabendo a população, apreciá-los, para que tenham consciência de como tem sido aplicado os recursos provenientes dos tributos, cabendo também ao contador, elaborá-los de forma honesta, pois sua função tem sido cada vez mais crucial, para a boa gestão pública.

\section{REFERÊNCIAS}

ÁVILA, Carlos Alberto de. Gestão Contábil para contadores e não contadores / Carlos Alberto de Ávila. - 2. Ed. Ver., atual e ampl. - Curitiba: Ibpex, 2011. 
BRASIL, República Federativa do. CONSTITUIÇÃO DA REPÚBLICA FEDERATIVA DO BRASIL. Senado, Brasília: 1988.

CONTABILIDADE, Conselho Federal de. RESOLUÇÃO №. 730/1993. Introduz as Normas Brasileiras de Contabilidade Aplicadas ao Setor Público. Brasília, 2008.

Ética Geral e Profissional em Contabilidade / Fundação Instituto de Pesquisas Contábeis, Atuariais e Financeiras; direção geral Eliseu Martins; coordenador Lázaro Plácido Lisboa. - 2. ed. - 13. reimpr. - São Paulo: Atlas, 2012.

LIMA, Diana Vaz de. Contabilidade Pública: integrando União, Estados e Municípios (Siafi e Siafem) / Diana Vaz de Lima, Róbison Gonçalves de Castro. - 3. ed. - 5. reimpr. - São Paulo: Atlas, 2012.

NOHARA, Irene Patrícia. Direito Administrativo / Irene Patrícia Nohara. - 2 ed. - São Paulo: Atlas, 2012.

PADOVEZE, Clóvis Luís, 1952 - Manual de Contabilidade Básica: Contabilidade introdutória e intermediária / Clóvis Luís Padoveze. - 8. ed. - São Paulo: Atlas, 2012. 